\title{
Results of a Pulmonologist Survey Regarding Knowledge and Practices With Inhalation Devices for COPD
}

\author{
Sidney S Braman MD, Brian W Carlin MD FAARC, Nicola A Hanania MD MSc, \\ Donald A Mahler MD, Jill A Ohar MD, Victor Pinto-Plata MD MSc, Tina Shah MD MPH, \\ David Eubanks EdD RRT, and Rajiv Dhand MD FAARC
}

\begin{abstract}
BACKGROUND: COPD guidelines advise on inhaled medication use, yet no advice is offered on when to use and which type of patient could benefit from a specific delivery device. We investigated pulmonologists' perception of their knowledge and practices with delivery devices for COPD management. METHODS: An online survey was designed by a steering committee of American Thoracic Society clinicians and scientists and conducted by a national market research firm between January 7 and 29, 2016. RESULTS: Two hundred and five respondents completed the survey. Nearly $80 \%$ of the respondents believed that they were very knowledgeable in COPD management and the use of medications; $68 \%$ believed that they were knowledgeable about preventing exacerbations. Ninety-eight percent of the respondents stated that they were at least somewhat knowledgeable about devices. Many respondents $\mathbf{( 7 0 \% )}$ stated that small-volume nebulizers were more effective than dry powder inhalers and pressurized metered-dose inhalers in the management of COPD exacerbations, and $63 \%$ believed that these were more effective in severe COPD (modified Medical Research Council dyspnea scale grade 4). Only 54\% of the respondents discussed device options with their patients. Physician screening for physical or cognitive impairments that could impact device choices was $53 \%$ and $16 \%$, respectively. Seventy percent of the respondents discussed device use, whereas $9 \%$ discussed cleaning and storage during a patient's first visit. Few respondents were very knowledgeable in teaching patients how to use devices $(43 \%)$ and, specifically, how to use $(32 \%)$ or clean and/or maintain $(20 \%)$ small-volume nebulizers. CONCLUSIONS: Most respondents were confident in their knowledge about treating COPD. Fewer respondents were confident about the use and maintenance of inhalation devices, and most respondents desired to learn more about inhalation devices. Key words: COPD; small-volume nebulizers; inhalation therapy. [Respir Care 2018;63(7):840-848. () 2018 Daedalus Enterprises]
\end{abstract}

\section{Introduction}

Inhaled medications have improved the quality of life for many patients with COPD. Well-established national and international protocols guide their use, with step-up medical therapy advised as the disease progresses..$^{1,2}$ Inhaled medications have been preferred because they give assurance that drug particles are deposited where they are needed. ${ }^{3,4}$

\footnotetext{
Dr Braman is affiliated with Icahn School of Medicine at Mount Sinai, New York, New York. Dr Carlin is affiliated with Sleep Medicine and Lung Health Consultants, Pittsburgh, Pennsylvania. Dr Hanania is affiliated with Baylor College of Medicine, Houston, Texas. Dr Mahler is affiliated with Geisel School of Medicine at Dartmouth, Hanover, New Hampshire and Valley Regional Hospital, Claremont, New Hampshire. Dr Ohar is affiliated with Wake Forest University School of Medicine, Winston-Salem, North Carolina. Dr Pinto-Plata is affiliated with Baystate Medical Center, Springfield, Massachusetts. Dr Shah is affiliated with TNT Health Enterprises, Atlanta, Georgia. Dr Eubanks is affiliated with
}

\footnotetext{
American Thoracic Society, Altamonte Springs, Florida. Dr Dhand is affiliated with University of Tennessee, Knoxville, Tennessee.

Dr Braman discloses relationships with Mayne Pharma, Covidien, Novartis, Genentech, and AstraZeneca. Dr Carlin discloses relationships with Sunovion, Boehringer-Ingelheim, Philips Respironics, Novartis, and Nonin. Dr Hanania discloses relationships with Novartis, Boehringer Ingelheim, GlaxoSmithKline, Astra Zeneca, Roche, Teva, Sanofi/Regeneron, Cheisi, and Genentech. Dr Mahler discloses relationships with
} 
Clinicians have several methods of inhaled delivery from which to choose. These include pressurized metered-dose inhalers (pMDIs), which provide a dose of a drug-propellant mixture after actuation from a pressurized can via a

\section{See the Related Editorial on Page 934}

metering valve; dry powder inhalers (DPIs), which are aerosols of fine particles of medication; soft mist inhalers, handheld, liquid inhalers that slowly deliver an aerosol cloud of fine particles; and small-volume nebulizers (SVNs), which generate aerosols by converting a liquid in solution or suspension into small droplets and by using continuous inhalation during tidal breathing. ${ }^{5}$ SVNs offer several advantages for drug delivery. They deliver high concentrations of drugs in the airways, have a rapid onset of action, are dosed at much lower than oral or parenteral alternatives, and result in minimal systemic absorption and, hence, few adverse effects.

Currently, guidelines and strategies for COPD offer no specific recommendations on when to use delivery devices and what patient type would benefit most from a specific device to achieve the best clinical outcomes. Guidelines that offer advice on nebulizers are $15^{6}$ and $20^{7}$ years old, and many clinicians may not be familiar with these reports. As we enter a new era of medicine in which researchers, providers, and patients work together to develop personalized care, new treatment strategies are needed to account for patient variability. ${ }^{8}$ This is especially important with COPD because improper use of inhaler devices

\footnotetext{
Mylan Specialty, Boehringer Ingelheim, GlaxoSmithKline, Novartis, Theravance, AstraZeneca UK, Sunovion, and Mayne Pharma. Dr Ohar discloses relationships with AstraZeneca, Novartis, Sunovion, Mylan, and Theravance. Dr Pinto-Plata discloses relationships with AstraZeneca, GlaxoSmithKline, and Mylan. Dr Dhand discloses relationships with AstraZeneca, Bayer, Cipla (India), GlaxoSmithKline and Sunovion. Dr Shah and Mr Eubanks have nothing to disclose.
}

Financial support for this study was provided to the American Thoracic Society by Sunovion Pharmaceuticals.

The study was performed at American Thoracic Society, New York, New York.

A version of this work was presented by Dr Braman at the American Thoracic Society International Conference, held May 13-18, 2016, in San Francisco, California.

Supplementary material related to this paper is available at http:// www.rcjournal.com.

Correspondence: Sidney S Braman MD, Icahn School of Medicine at Mount Sinai, One Gustav L Levy Place, Box 1232, New York, NY 10029. E-mail: sidney.braman@mssm.edu.

DOI: $10.4187 /$ respcare. 05717

\section{QUICK LOOK}

\section{Current knowledge}

National and international guidelines and strategies advise on the management of COPD with inhaled medications but offer no specific recommendations on which or when to use a specific delivery device. When prescribing inhaled medication for COPD, physicians may not adequately consider specific criteria pertinent to device selection that may help patients achieve the best clinical outcome.

\section{What this paper contributes to our knowledge}

U.S.-based pulmonologists believed that they were very knowledgeable about COPD management with inhaled medications, but fewer were knowledgeable about selection criteria for a certain device and how to use, clean, and maintain a device. Most pulmonologists believed that small-volume nebulizers were more effective in patients with severe symptoms and exacerbations, recommended them earlier in COPD management when symptoms were more severe, and expressed a need for more education on inhalation devices for COPD management.

has been shown to affect drug delivery ${ }^{9}$ and that may adversely affect outcomes. ${ }^{10}$

A number of factors influence a clinician's choice of inhalation device for patients with COPD: patient age, acute or chronic need, disease state and disease severity, comorbid illnesses, patient frailty, patient preferences, and cost to the patient. Because current COPD guidelines offer no specific directions to clinicians on the choice of inhalation devices that can suit individual patients, we hypothesized that prescribing physicians may not adequately consider specific criteria pertinent to device selection when prescribing inhaled medication for COPD. The objective of this investigation was to better understand pulmonologists and pulmonary fellows perception of their knowledge and their practices regarding the treatment of COPD with inhalation devices, with particular attention to the use of SVNs.

\section{Methods}

An online survey was designed by a steering committee of 9 American Thoracic Society (ATS) clinicians and scientists (the authors). The survey explored pulmonologists' perception of personal knowledge and experience with COPD treatment; treatment options; the use of inhalation devices, including handheld SVNs; and their interest in 
supplemental education on these topics. This survey was submitted to the University of Tennessee Institutional Review Board and was determined to be exempt according to 45 CFR 46.101(b)(2). ${ }^{11}$

The survey was composed of multiple-choice questions (see the supplementary materials at http://www. rcjournal.com). Steering committee members achieved consensus on the content, wording, and formatting of each question. No formal measures of the survey's validity or reliability were made. A total of 27 questions explored COPD treatment knowledge, medication options, and use of inhalation devices. These questions included additional supporting questions that developed detailed responses within the 27 primary questions. Adaptive questioning was used to reduce survey complexity. Questions that generally assessed opinions were composed of 4 responses (strongly disagree, somewhat disagree, somewhat agree, strongly agree). Questions that assessed general knowledge level were composed of 6 responses (not at all knowledgeable, not very knowledgeable, somewhat knowledgeable, knowledgeable, very knowledgeable, and extremely knowledgeable). Questions that assessed specific knowledge were composed of detailed multiple-choice answers from which the respondent could select those that best reflected his or her personal experience. The knowledge, opinion, and experience questions were presented in randomized order to prevent bias. Nonresponse options, such as "not sure," "not applicable," or "decline to answer," were included as potential responses. The survey consisted of 2 parts and was expected to be completed in 20-25 min. Part 1 addressed the pulmonologists' demographics and practice information. Part 2 addressed knowledge and practices specific to COPD management and inhaler use.

Pulmonologists and pulmonology fellows were recruited from the ATS membership roster and/or were attendees of the ATS 2015 conference. Physicians from these sources and who expressed special interest or expertise in COPD management were solicited via e-mail. The responses from only U.S. pulmonologists and fellows were included in this report, and only complete surveys were analyzed. A sample size of $>100$ respondents supported quantitative analysis. The survey was conducted by a Harris Poll (Harris Insights \& Analytics, Rochester, New York) between January 7 and 29, 2016. Duplicate entries were prevented electronically. Findings are presented based on recommendations for reporting results of web-based surveys. ${ }^{12}$ Enrolled subjects were reminded that identities are not disclosed and that all responses are strictly confidential. All data are reported for groups and not for individuals. Data are presented as percentages of the stated population. Because the subjects were self-selected rather than a prob- ability sample, no estimates of sampling error were calculated for the survey results.

\section{Results}

More than 6,200 pulmonologists and fellows from around the world who expressed special interest or expertise in COPD management were solicited via e-mail from the ATS membership roster and from attendees of the ATS 2015 conference. A total of 205 pulmonologists and fellows in the United States completed the survey in its entirety. Pulmonary/critical care fellows in training comprised $18.5 \%$ of the respondents. Of those, nearly half were in the third or fourth year of training (Table 1). Forty-eight percent of the practicing pulmonologists and $74 \%$ of the fellows were responsible for the care of up to 10 patients with COPD per week. More than half of patients with COPD were referred to pulmonologists from primary care physicians. Other patients were directed to a pulmonologist by an emergency department or other physicians; $11.7 \%$ seemed to be self-referred. Twice the percentage of fellows saw patients with COPD who were referred to them from the emergency department. Physicians were asked to judge the severity of their patients' COPD by using the modified Medical Research Council dyspnea scale (mMRC). ${ }^{13}$ They reported that half of their patients were grade 3 or 4 .

A high proportions of pulmonologists and fellows expressed strong knowledge of medications to treat COPD and exacerbation prevention (Fig. 1). Nearly $80 \%$ of respondents stated that they were very knowledgeable about COPD medications and management, and $68 \%$ believed that they were knowledgeable about preventing exacerbations. More than half of the respondents categorized themselves as very knowledgeable about treatment devices, whereas $98 \%$ stated they were at least somewhat knowledgeable. A minor proportion of the respondents believed that they were very knowledgeable in teaching patients how to use (43\%) or clean and maintain (22\%) the devices. Seventy percent reported that they typically discussed how to use the device during a patient's first visit, whereas only 9\% discussed how to clean and store devices. A high proportion of the respondents expressed interest in gaining more education about any of these topics.

Further analysis of responses by pulmonologists and fellows that pertained to treatment devices demonstrated lesser confidence in specific knowledge areas (Fig. 2). Approximaely one third of the pulmonologists and fellows stated that they were knowledgeable or extremely knowledgeable about SVNs, including the intended use of the device, when it should be used, how to use it, and who should use it. Even fewer pulmonologists and fellows, approximately one fifth, stated that they were very or ex- 
Table 1. Demographics and Practice Characteristics

\begin{tabular}{|c|c|c|c|c|c|}
\hline & \multirow{2}{*}{$\begin{array}{c}\text { Practicing } \\
\text { Pulmonologists, } \% \\
(n=167)\end{array}$} & \multicolumn{4}{|c|}{$\begin{array}{c}\text { Fellows in } \\
\text { Training, } \%(n=38)\end{array}$} \\
\hline & & 1 st $\mathrm{Y}, 23 \%$ & 2nd $Y, 29 \%$ & 3rd Y, 45\% & 4th Y, $3 \%$ \\
\hline \multicolumn{6}{|c|}{ No. patients with COPD seen } \\
\hline 1-5/week & 20 & \multicolumn{4}{|c|}{41} \\
\hline $6-10 /$ week & 28 & \multicolumn{4}{|c|}{32} \\
\hline $11-15 /$ week & 11 & \multicolumn{4}{|c|}{11} \\
\hline 16-20/week & 14 & \multicolumn{4}{|c|}{8} \\
\hline$>21 /$ week & 27 & \multicolumn{4}{|c|}{8} \\
\hline \multicolumn{6}{|c|}{ Mean proportion of patients referred by } \\
\hline PCP & 58.1 & \multicolumn{4}{|c|}{53.0} \\
\hline ED & 11.3 & \multicolumn{4}{|c|}{22.1} \\
\hline Allergist & 3.4 & \multicolumn{4}{|c|}{3.1} \\
\hline Other & 15.5 & \multicolumn{4}{|c|}{13.5} \\
\hline Not referred & 11.7 & \multicolumn{4}{|c|}{8.3} \\
\hline \multicolumn{6}{|c|}{ Mean proportion of patients classified by mMRC scale grade } \\
\hline 0 & 5.2 & \multicolumn{4}{|c|}{6.4} \\
\hline 1 & 14.8 & \multicolumn{4}{|c|}{16.5} \\
\hline 2 & 29.0 & \multicolumn{4}{|c|}{28.2} \\
\hline 3 & 33.5 & \multicolumn{4}{|c|}{32.2} \\
\hline 4 & 17.5 & \multicolumn{4}{|c|}{16.7} \\
\hline
\end{tabular}

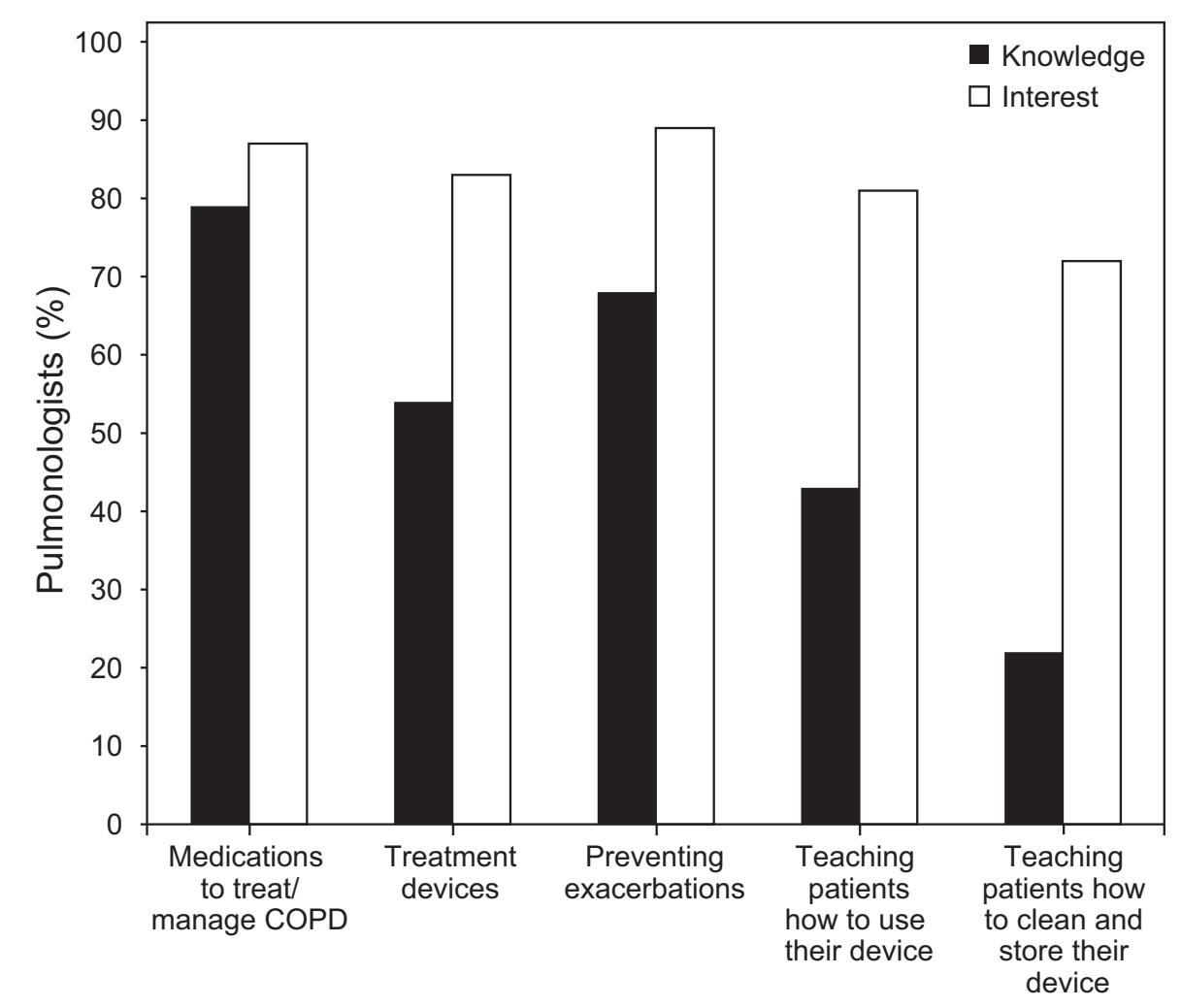

Fig. 1. Pulmonologists' responses regarding their knowledge and interest for further education. 


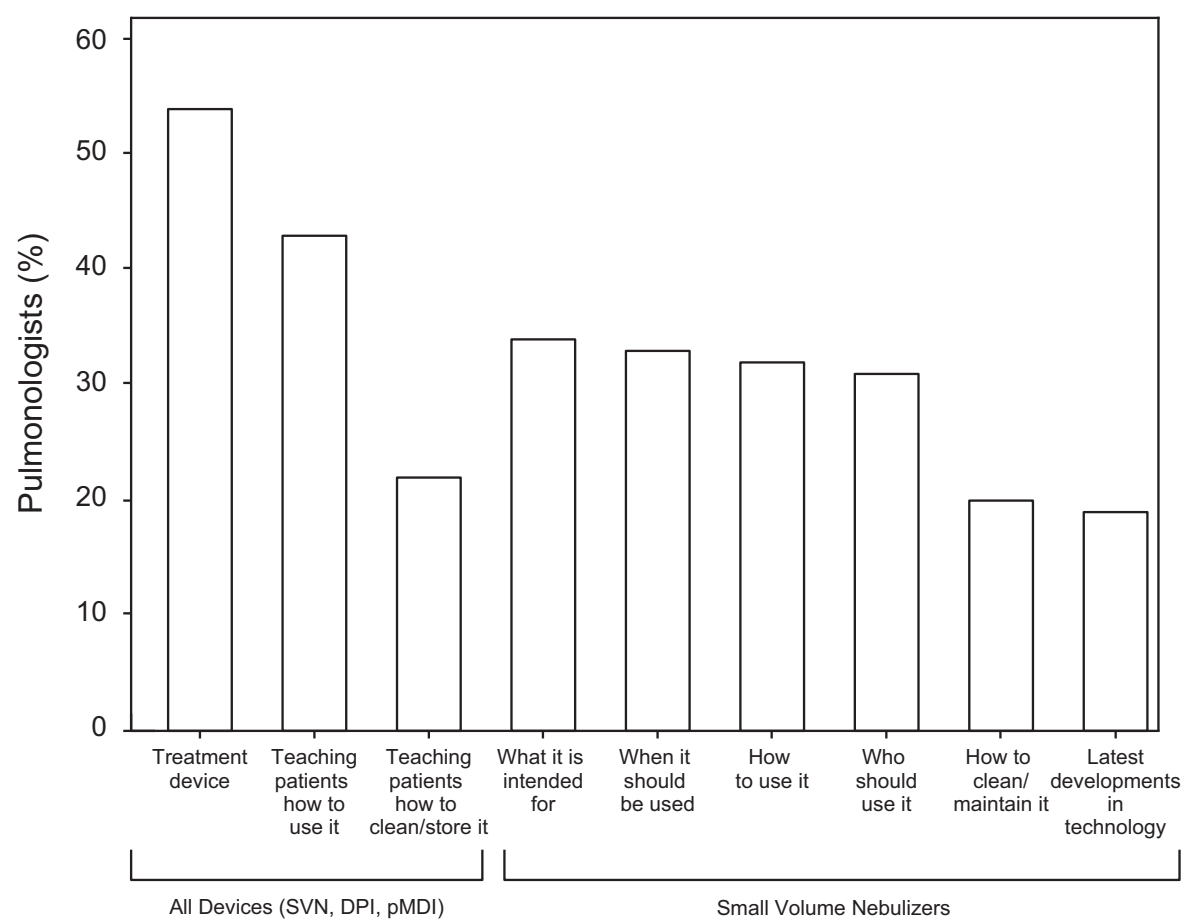

Fig. 2. Percentage of pulmonologists who were knowledgeable or extremely knowledgeable about inhalation devices. SVN $=\mathbf{s m a l l - v o l u m e}$ nebulizer; DPI = dry powder inhaler; pMDI = pressurized metered-dose inhaler.

tremely knowledgeable about cleaning and maintenance of SVNs or new technologies that pertain to SVNs.

When considering the interaction between pulmonologists or fellows and their patients with COPD, approximately half of the pulmonologists and fellows assessed or advised patients on inhalation devices available to them (Fig. 3). Only 54\% of the respondents discussed device options with their patients. Furthermore, only 53\% stated that they screened for physical impairments that could impact delivery device choices and that only $16 \%$ screened for cognitive impairment. Very few (7\%) respondents referred patients to a respiratory therapist to assist patients with inhalation devices, and $24 \%$ directed patients to support groups or web sites that can offer advice to patients.

Some pulmonologists and fellows were very comfortable with the use of SVNs and which patients should receive them for inhaled medications. Thirty-one percent believed that they were extremely/very knowledgeable about which patients should use SVNs, and 56\% believed that SVNs were essential for some patients. Many pulmonologists and fellows recommended SVNs based on COPD symptoms of dyspnea and the occurrence of exacerbations (Table 2). Recommendations for early use of SVNs were made by $52 \%$ of pulmonologists and fellows for patients with COPD with mMRC grade 4 . Thirty-one percent recommended early SVN use for mMRC grade 3 and $16 \%$ recommended early SVN use for mMRC grade 2. Similarly, 59\% recommended SVNs early in COPD after
COPD exacerbations. For patients with more-severe COPD, as measured by an mMRC grade of $4,63 \%$ of the pulmonologists and fellows believed that handheld SVNs were more effective than DPIs and/or pMDIs. Seventy percent stated that handheld SVNs were more effective than DPIs and/or pMDIs in the management of COPD exacerbations.

The survey provided evidence that more education is needed with respect to SVNs. Eighty-three percent of the respondents reported interest in receiving additional education on COPD treatment devices, and $84 \%$ agreed that they would like to learn about different types of nebulizers.

\section{Discussion}

A variety of inhalation devices are used for drug delivery to patients with COPD. ${ }^{3}$ However, current guidelines offer no guidance on the specific devices that should be used in a variety of clinical settings to achieve optimal outcomes. As specialists who routinely manage patients across the spectrum of COPD severity, pulmonologists are likely to have a significant influence on the number and type of prescriptions for inhalation devices and on the choices of other health-care professionals when selecting these devices. Accordingly, the present investigation surveyed the knowledge and practices of pulmonologists and fellows who expressed specific interest in COPD and its management regarding the treatment of COPD with inhalation devices. These respondents, because of their ex- 


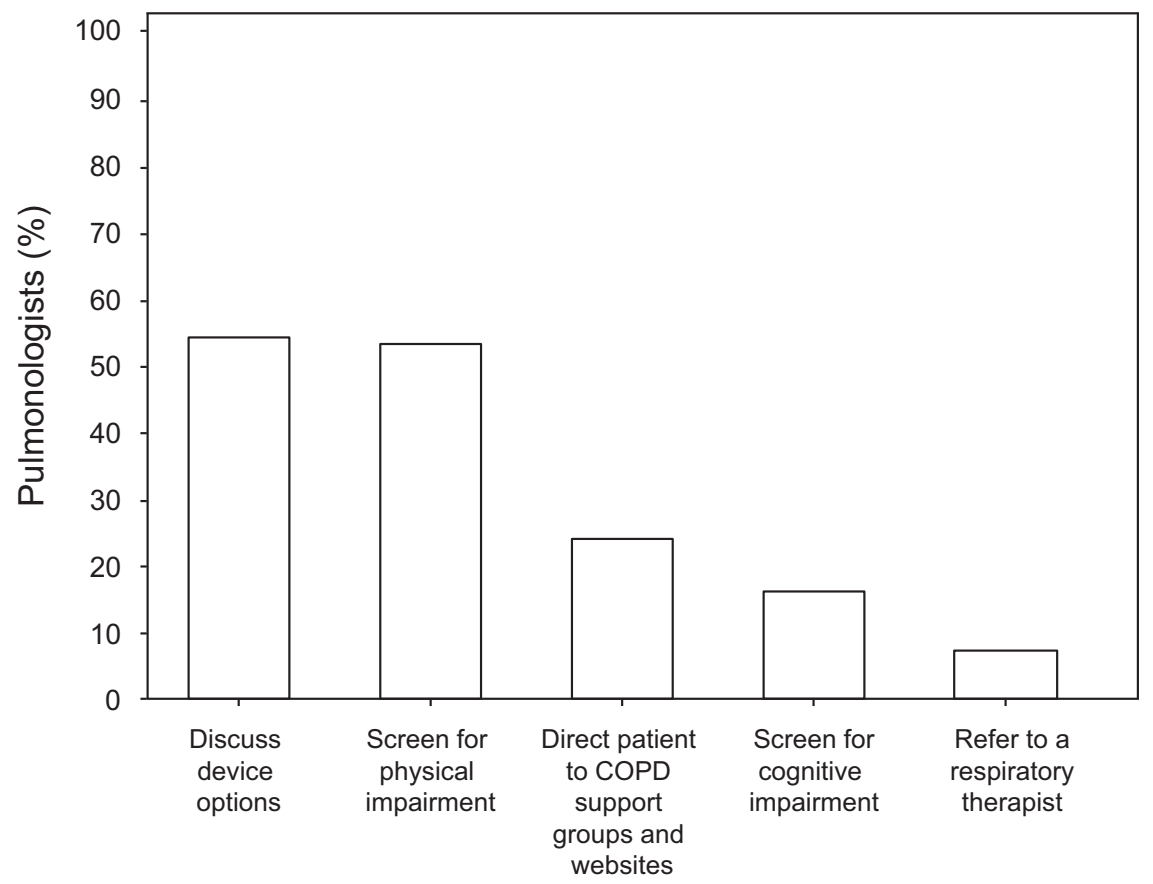

Fig. 3. Percentage of pulmonologists who assessed and advised patients.

Table 2. Percentage of Pulmonologists and Fellows Who Recommended Handheld Small-Volume Nebulizers According to Symptom Status

\begin{tabular}{|c|c|c|c|c|c|c|}
\hline & \multicolumn{5}{|c|}{ mMRC Grade } & \multirow{2}{*}{$\begin{array}{l}\text { After an } \\
\text { Exacerbation }\end{array}$} \\
\hline & 0 & 1 & 2 & 3 & 4 & \\
\hline \multicolumn{7}{|l|}{ When do you typically recommend a nebulized medication, $\%$} \\
\hline Early in treatment & 4 & 10 & 16 & 31 & 52 & 69 \\
\hline Later in treatment & 7 & 20 & 36 & 52 & 41 & 26 \\
\hline Do not recommend & 89 & 70 & 48 & 17 & 7 & 5 \\
\hline $\begin{array}{l}\text { For which patient group do you find handheld small-volume } \\
\text { nebulizers more effective than pMDIs or DPIs, \% }\end{array}$ & 5 & 5 & 15 & 42 & 63 & 70 \\
\hline $\begin{array}{l}\text { mMRC }=\text { Modified Medical Research Council dyspnea scale } \\
\text { pMDIs }=\text { pressure metered-dose inhalers } \\
\text { DPI }=\text { dry powder inhaler }\end{array}$ & & & & & & \\
\hline
\end{tabular}

pressed interest, were expected to be the most knowledgeable and patient-centered providers for patients with COPD; presumably, physicians with less interest in COPD and, especially, primary care physicians would likely be less knowledgeable and comfortable with choices about COPD treatment devices.

The main results demonstrated that pulmonologists and fellows reported believing that they were knowledgeable with the diagnosis and management of COPD, the prevention and management of exacerbations, and the use of COPD medications. Barely a majority believed that they were very knowledgeable about the various delivery devices used for the treatment of COPD, and even fewer reported being very knowledgeable about SVNs. Few pulmonologists and fellows thought that they were knowledgeable about how to use, clean and maintain, and store inhalation devices. This was further reflected by a larger proportion of the surveyed physicians who responded that they were not comfortable with teaching these aspects to patients. Approximately half of respondents screened patients with COPD for physical impairments that could impact the choice of delivery device or even discussed device options with their patients. The majority of pulmonologists and fellows recommended SVNs early in the management of COPD only when symptoms were more severe or the patient's symptoms had recently been exacerbated, because they believed that SVNs were more effective than pMDIs and DPIs in these clinical settings. Despite their daily clinical experience and knowledge about inhalation devices, the re- 
spondents recognized the need for more education about the place of nebulizers in COPD management.

This investigation had several limitations. No formal measures of the survey's validity or reliability were made. The pulmonologist sample was biased in that only those who stated special interest in COPD and who had an ATS membership and/or attended the 2015 ATS annual meeting were recruited. Pulmonologists required online access and the ability to participate in an online survey. Furthermore, pulmonologists were self-selected based on their interest in the survey topic and may have had opinions that differed from a randomly selected pulmonologist population. The pulmonologists' patients were not surveyed simultaneously to validate the responses or the impact of the responses on health care. In addition, the frequency of medication switches and replacement of SVNs were not addressed. In this pulmonologist population, it is a reasonable expectation that those most skilled and interested in the management of COPD would be those who responded to the survey. Therefore, it is possible that the results of this survey underestimated the knowledge gaps identified.

DPIs or pMDIs are routinely used by patients with COPD for maintenance therapy. For optimal clinical benefit, it is necessary to carefully and appropriately match the aerosol delivery system to the patient's needs. ${ }^{3}$ A systematic review concluded that therapy for patients with stable COPD and those with a COPD exacerbation was equally effective with various inhalation devices (pMDIs, DPIs, and SVNs) if the patients used the devices with an optimal technique. ${ }^{14}$ However, in most $\beta$-agonist trials that were reviewed, single-dose strengths delivered by different devices were compared. ${ }^{14}$ These doses often approximated the plateau of the dose-response curve, which made it difficult to differentiate any difference in efficacy among the devices.

In the present study, $54 \%$ of the respondents stated that they were extremely/very knowledgeable about the devices used in treatment for COPD, and $43 \%$ responded that they were very knowledgeable about teaching patients how to use the devices. Furthermore, approximately one third of the respondents believed that they were very knowledgeable about what use the SVNs are intended, who should use them, and when and how they should be used. These observations are consistent with several previous investigations, which documented that physicians need more education and training in both written and practical aspects of pMDI and DPI use..$^{15-18}$

The respondents perceived that SVNs were more efficacious than pMDIs or DPIs as the severity of the disease increased and after a COPD exacerbation. Likewise, respondents in a previous survey in France, which included pulmonologists, reported that they prescribed nebulizers to achieve greater efficacy and to administer high dosages, and because active involvement of the patients was not needed to obtain therapeutic benefits with nebulized drugs. ${ }^{19}$ The higher efficacy of nebulizers was also perceived by patients with more-severe chronic lung disease and symptoms who regularly use nebulizers at home. ${ }^{20}$

Misuse of pMDIs and DPIs is highly prevalent. ${ }^{21,22}$ Studies that reported direct observation of patients' inhaler technique by trained personnel reveal that, despite efforts in education, training, and device development, misuse of these agents has not improved in the past 40 years. ${ }^{22} \mathrm{~Pa}$ tients who incorrectly use these inhalation devices may not achieve full therapeutic benefits. Poor technique has been associated with an increased risk of hospitalization, emergency department visits, courses of oral corticosteroids, and overall poor disease control. ${ }^{21}$ SVNs have the advantage that patients can use tidal breathing over several minutes and no special breathing techniques need to be used or are required. In contrast, drugs delivered with one or two breaths by pMDIs or DPIs may be inadequate if the breathing technique is not optimal. With an optimal technique of administration, pMDIs and DPIs are effective in patients with COPD. However, there are clinical circumstances when nebulizers may be preferable for maintenance therapy. ${ }^{23}$ Poor inhalation technique in patients with COPD has been associated with older age, poor vision, and low health literacy. ${ }^{21,24}$ The advantages of SVNs must also be appropriately weighed against the drawbacks that some patients find with SVNs. A minority of subjects who were surveyed about their knowledge and practices with inhalation devices, found SVNs to be time consuming (18\%), burdensome (9\%), complicated (4\%), or expensive (24\%). ${ }^{25}$

Other factors that may influence the choice of an aerosol delivery device include the availability of the drug and device, personal preferences, convenience, the ability to use the device, the ability and necessity to regularly clean and replace SVNs, the cost to the patient, and the availability of competent caregivers. ${ }^{26-28}$ A market survey conducted in 2008 indicated that almost half of patients with COPD had nebulizers and more than two thirds of such patients used nebulizers on a regular basis. ${ }^{23}$ Thus, based on the prevalence of the disease, ${ }^{29}$ millions of patients with COPD in the United States use nebulizers on a regular basis at home. In addition, use of SVNs for maintenance ambulatory therapy has become a routine practice for a variety of inhaled agents in patients with cystic fibrosis. ${ }^{30,31}$ Despite the well-known advantages of pMDIs and DPIs as well as the drawbacks of SVN use, the respondents in our survey believed that SVNs also have a place for maintenance therapy of COPD, especially in patients with more-severe symptoms. This seems to be a widespread practice because a survey in Italy found that subjects with chronic air-flow obstruction who used nebulizers for maintenance therapy in addition to inhalers were older, had more-severe disease, more symptoms, and greater utilization of health-care resources than subjects who only used inhalers. ${ }^{20}$ These considerations apparently influenced 
pulmonologists in our survey who used SVNs early in treatment of patients with severe dyspnea and with those who had experienced a COPD exacerbation.

In the present study, the responses of the pulmonologists regarding their knowledge about COPD symptoms, disease management, and use of inhalation devices were consistent with their training and clinical practice. Although the majority of the respondents believed that they had adequate knowledge and expertise about inhalation devices, a large number $(>80 \%)$ expressed interest in receiving additional education on more-specific aspects of COPD treatment. The desire by most pulmonologists to learn more about inhalation devices, especially SVNs, may reflect the lack of formal education in the use of these devices. In a similar survey of physicians in Turkey, the majority of whom were pulmonologists and pediatricians with experience in using inhalation devices, $<20 \%$ of the respondents reported adequate knowledge about inhalation devices and administration techniques, but the majority rated their knowledge about SVNs as completely or highly satisfactory. ${ }^{32}$ The majority of these physicians also believed that SVNs were easy to teach about and use, and that their patients used them correctly more often than other inhalation devices. ${ }^{32}$

Even if most respondents could train patients in the use of these devices, more than half of the respondents did not know which SVNs were being used by their patients (data not shown). This decision was often made by the durable medical equipment supplier without the active participation or involvement of the clinical team involved in the patient's care. Moreover, there was no consensus about who (physician, nurse, respiratory therapist, pharmacist, or durable medical equipment supplier) should be instructing patients in the appropriate use of SVNs. Our findings were also consistent with a previous survey in Italy of subjects who used nebulizers at home. In that study, $>60 \%$ of the respondents did not receive any information from their health-care advisers about the correct method to use their nebulizer and $>75 \%$ did not receive information about cleaning and care of their nebulizer. ${ }^{33}$

Contamination of nebulizer solutions has been linked to an outbreak of nosocomial pneumonia. ${ }^{34}$ The recommendation for home nebulizers is to clean, disinfect, rinse (if needed), and air dry after each use. ${ }^{35}$ There seemed to be a significant knowledge gap among the pulmonologists in this survey, with only approximately $70 \%$ who responded that device decontamination was absolutely essential or very important (data not shown). As many as $60 \%$ of the respondents believed that they did not have adequate knowledge about the cleaning and maintenance of SVNs, and only $9 \%$ of the respondents discussed cleaning and storage of the inhalation devices with their patients during their first visit.

The views of physician respondents in a previous sur$v^{2} y^{32}$ and also in the present survey showed that there is a need for more information about inhalation devices. This presents an educational opportunity that should be addressed during fellowship training and beyond. Information should include knowledge about all of the delivery systems and also how to offer a device that will be concordant with the patient's medical needs, preferences, and lifestyle. ${ }^{36}$ An overwhelming majority of patients and caregivers are very satisfied with nebulization therapy and have seen benefits in symptom relief, ease of use, and improved quality of life. ${ }^{37}$ The lack of formal training of physicians in the use of inhalation devices such as SVNs may be one of the factors that contributed to misuse or mishandling of devices among patients. Direct formal training on devices may be an important approach to improve outcomes. Other educational approaches can include the broader use of structured, interprofessional, team-based education, and care that is prominent in contemporary academic settings. It is possible that addressing this knowledge gap among pulmonologists could improve clinical outcomes of many patients with COPD and have a major impact on the consumption of resources associated with exacerbations and hospitalizations. This might lead to a significant reduction of health expenditures for COPD. ${ }^{38}$

\section{Conclusions}

This survey found that U.S.-based pulmonologists believed that they were very knowledgeable about COPD management and prevention of exacerbations. Most pulmonologists would recommend SVNs earlier in management of patients with severe symptoms and for a COPD exacerbation, with the belief that SVNs are more effective in these clinical settings. Fewer respondents were knowledgeable about inhalation devices, which patients with COPD should use certain types of device, how to use devices, and device maintenance and cleaning. The study disclosed an unmet need for more knowledge among pulmonologists regarding various inhalation devices used for COPD management.

\section{ACKNOWLEDGMENTS}

The authors thank the ATS and Sunovion Pharmaceuticals for their collaboration and support of this research and manuscript development, the participants who took the time to complete the survey, and Medical Dynamics, New York, New York, for their editorial services.

\section{REFERENCES}

1. Celli BR, MacNee W; ATS/ERS Task Force. Standards for the diagnosis and treatment of patients with COPD: a summary of the ATS/ERS position paper. Eur Respir J 2004 23(6):932-946.

2. From the Global Strategy for the Diagnosis, Management and Prevention of COPD, Global Initiative for Chronic Obstructive Lung Disease (GOLD) 2017. http://goldcopd.org. Accessed May 1, 2017.

3. Dolovich MB, Dhand R. Aerosol drug delivery: developments in device design and clinical use. Lancet 2011;377(9770):1032-1045. 


\section{Pulmonologist Survey of Inhalation Devices}

4. Darquenne C. Aerosol deposition in health and disease. J Aerosol Med Pulm Drug Deliv 2012;25(3):140-147.

5. Pirozynski M, Sosnowski TR. Inhalation devices: from basic science to practical use, innovative vs generic products. Expert Opin Drug Deliv 2016;13(11):1559-1571.

6. Boe J, Dennis JH, O’Driscoll BR, Bauer TT, Carone M, Dautzenberg B, et al; European Respiratory Society Task Force on the use of nebulizers. European Respiratory Society Guidelines on the use of nebulizers. Eur Respir J 2001;18(1):228-242.

7. O'Donohue WJ Jr. Guidelines for the use of nebulizers in the home and at domiciliary sites. Report of a consensus conference. National Association for Medical Direction of Respir Care (NAMDRC) Consensus Group. Chest 1996;109(3):814-820.

8. Collins FS, Varmus H. A new initiative on precision medicine. N Engl J Med 2015;372(9):793-795.

9. Lavorini F, Fontana GA, Usmani OS. New inhaler devices-the good, the bad and the ugly. Respiration 2014;88(1):3-15.

10. Rau JL. Practical problems with aerosol therapy in COPD. Respir Care 2006;51(2):158-172.

11. Code of Federal Regulations, Title 45, Part 46. Protection of human subject. https://www.hhs.gov/ohrp/regulations-and-policy/regulations/ 45-cfr-46/index.html. Accessed December 1, 2015.

12. Eysenbach G. Improving the quality of web surveys: the checklist for reporting results of internet e-surveys (CHERRIES). J Med Internet Res 2004;6(3):e34.

13. Bestall JC, Paul EA, Garrod R, Garnham R, Jones PW, Wedzicha JA. Usefulness of the Medical Research Council (MRC) dyspnoea scale as a measure of disability in patients with chronic obstructive pulmonary disease. Thorax 1999;54(7):581-586.

14. Dolovich MB, Ahrens RC, Hess DR, Anderson P, Dhand R, Rau JL, et al; American College of Chest Physicians; American College of Asthma, Allergy, and Immunology. Device selection and outcomes of aerosol therapy: evidence-based guidelines. Chest 2005;127(1): 335-371.

15. Guidry GG, Brown WD, Stogner SW, George RB. Incorrect use of metered dose inhalers by medical personnel. Chest 1992;101(1):31-33.

16. Interiano B, Guntupalli KK. Metered-dose inhalers. Do health care providers know what to teach? Arch Intern Med 1993;153(1):81-85.

17. Hanania NA, Wittman R, Kesten S, Chapman KR. Medical personnel's knowledge of and ability to use inhaling deices. Metered-dose inhalers, spacing chambers, and breath-actuated dry powder inhalers. Chest 1994;105(1):111-116.

18. Alismail A, Song CA, Terry MH, Daher N, Almutairi WA, Lo T. Diverse inhaler devices: a big challenge for health-care professionals. Respir Care 2016;61(5):593-599.

19. de Monte M, Scruignec J, Dubus JC, Chaumuzeau JP, Dautzenberg B, Dessanges JF, et al. GAT. N.U.A.G.ES: A survey of nebulisation practice in France with regard to ERS guidelines. Respir Med 2007; 101(12):2561-2565.

20. Melani AS, Canessa P, Coloretti I, DeAngelis G, DeTullio R, DelDonno M, et al.; Educational Study Group of the Italian Association of Hospital Pulmonologists (AIPO). Inhaler mishandling is very common in patients with chronic airflow obstruction and long-term home nebuliser use. Respir Med 2012;106:668-676.

21. Melani AS, Bonavia M, Cilenti V, Cinti C, Lodi M, Martucci P, et al.; Gruppo Educazionale Associazione Italiana Pneumologi Os- pedalieri. Inhaler mishandling remains common in real life and is associated with reduced disease control. Respir Med 2011;105(6): 930-938.

22. Sanchis J, Gich I, Pedersen S; on behalf of the Aerosol Drug Management Improvement Team (ADMIT). Systematic review of errors in inhaler use. Has patient technique improved over time? Chest 2016;150(2):394-406.

23. Dhand R, Dolovich M, Chipps B, Myers TR, Restrepo R, Farrar JR. The role of nebulized therapy in the management of COPD: evidence and recommendations. COPD 2012;9(1):58-72.

24. Press VG, Arora VM, Shah LM, Lewis SL, Ivy K, Charbeneau J, et al. Misuse of respiratory inhalers in hospitalized patients with asthma or COPD. J Gen Intern Med 2011;26(6):635-642.

25. Dhand R, Mahler DA, Carlin B, Hanania N, Ohar J, Pinto-Plata V, et al. Results of a patient survey regarding COPD knowledge, treatment experiences, and practices with inhalation devices. Respir Care 2018 Mar 20. [Epub ahead of print].

26. Souza ML, Meneghini AC, Ferraz E, Vianna EO, Borges MC. Knowledge of and technique for using inhalation devices among asthma patients and COPD patients. J Bras Pneumol 2009;35(9):824-831.

27. Myers TR. The science guiding selection of an aerosol delivery device. Respir Care 2013;58(11):1963-1973.

28. Goodman DE, Israel E, Rosenberg M, Johnston R, Weiss ST, Drazen JM. The influence of age, diagnosis, and gender on proper use of metered-dose inhalers. Am J Respir Crit Care Med 1994; 150(5 Pt 1):1256-1261.

29. COPD e-Newsletter. Available at http://www.nhlbi.nih.gov/health/ public/lung/copd/. Accessed August 2, 2016.

30. Kesser KC, Geller DE. New aerosol delivery devices for cystic fibrosis. Respir Care 2009;54(6):754-767; discussion 767-768.

31. Agent $P$, Parrott $H$. Inhaled therapy in cystic fibrosis: agents, devices and regimens. Breathe (Sheff) 2015;11(2):111-118.

32. AZ, C, Ceylan E, Pekcan S, Yılmaz Ö, Öztürk S, et al. The knowledge and considerations of the physicians regarding the inhaler devices in asthma and COPD: the INTEDA-1 study. Tuberk Toraks 2013;61(3):183-192.

33. Melani AS, Sestini P, Aiolfi S, Barbato N, Canessa P, De Angelis G, et al.; Associazone Italiana Pneumologi Ospedalieri (AIPO) Educational Group. GENebu Project: home nebulizer use and maintenance in Italy. Eur Respir J 2001;18(5):758-763.

34. Cobben NA, Drent M, Jonkers M, Wouters EF, Vaneechoutte M, Stobberingh EE. Outbreak of severe Pseudomonas aeruginosa respiratory infections due to contaminated nebulizers. J Hosp Infect 1996;33(1):63-70.

35. O'Malley CA. Device cleaning and infection control in aerosol therapy. Respir Care 2015;60(6):917-927; discussion 928-930.

36. Fromer L, Goodwin E, Walsh J. Customizing inhaled therapy to meet the needs of COPD patients. Postgrad Med 2010;122(2):83-93.

37. Sharafkhaneh A, Wolf RA, Goodnight S, Hanania NA, Make BJ, Tashkin DP. Perceptions and attitudes toward the use of nebulized therapy for COPD: patient and caregiver perspectives. COPD 2013; 10(4):482-492.

38. Roggeri A, Micheletto C, Paola Roggeri D. Inhalation errors due to device switch in patients with chronic obstructive pulmonary disease and asthma: critical health and economic issues. and economic issues. Int J Chronic Obstruct Pulmon Dis 2016;11:597-602.

This article is approved for Continuing Respiratory Care Education credit. For information and to obtain your CRCE

(free to AARC members) visit www.rcjournal.com

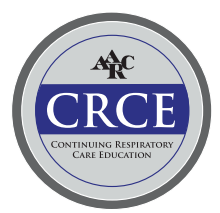

